\title{
Supersonic Flow Analysis and Evaluation of Damping derivative
}

\author{
Renita Sharon Monis ${ }^{1}$, Aysha Shabana ${ }^{2}$, Asha Crasta ${ }^{3}$, S.A.Khan ${ }^{4}$ \\ ${ }^{1,2}$ Research Scholar, Department of Mathematics, M.I.T.E, Moodabidri \\ ${ }^{3}$ Associate Professor, Department of Mathematics, M.I.T.E, Moodabidri \\ ${ }^{4}$ Professor, Mechanical Engineering Department, IIUM, Kuala Lumpur, Malaysia.
}

\begin{abstract}
The emphasis of this paper is to examine the variation of damping derivative with incidence angle and Mach number with varying pivot position. The damping derivative decreases with Mach number and increases with the incidence angle. It is also seen that for a given Mach number the damping derivatives are decreasing and reaches a minimum value and then again increases and attains the same value which was at $h$ $=0$, for pivot position $h=0$ to $h=1.0$ and at $h=0.5$ it attains a minima and increases for $h=0.6$ to $h=1$.

The Damping derivative decreases with Mach number for the varying pivot position.
\end{abstract}

Keywords: Damping derivative, pivot position, Stability derivative, Supersonic flow.

\section{Introduction}

Ghosh and Mistry [1] have given a hypersonic flow theory for the oscillating 2-D wedge for quasi steady flow which has been further extended by Ghosh [2] to solve the axi-symmetric flow problem. Crasta and khan [4 to 28] have taken Ghosh's [3] large deflection similitude into consideration to develop an unsteady piston theory for the prediction of stability derivatives of oscillating planar and non-planar wedges in supersonic and hypersonic flow. Here an attempt is made to analyze the variation of damping derivative with Mach number and incidence angle for various pivot position from $\mathrm{h}=0$ to 1 .

The expression for pressure ratio given by

\section{Analysis}

$\frac{p}{p_{\infty}}=1+A M_{\infty}^{2} \sin ^{2} \alpha+A M_{\infty} \sin \alpha \sqrt{B+M_{\infty}^{2} \sin ^{2} \alpha}$

A piston theory which has been used in above equation has been extended to supersonic flow by dividing with $\cos \Phi$ term. The expression is given below:

$$
\begin{aligned}
& \frac{p}{p_{\infty}}=1+A\left(\frac{M_{p}}{\cos \phi}\right)^{2}+A\left(\frac{M_{p}}{\cos \phi}\right)\left(B+\left(\frac{M_{p}}{\cos \phi}\right)^{2}\right)^{\frac{1}{2}} \\
& \text { Where } \\
& \boldsymbol{A}=\frac{\boldsymbol{\gamma ( \gamma + 1 )}}{\mathbf{4}} \\
& \boldsymbol{B}=\left(\frac{\mathbf{4}}{\gamma+\mathbf{1}}\right)^{2}
\end{aligned}
$$

The nose down moment is given by

$$
-m=\int_{0}^{L}\left(x-x_{0}\right) p d x
$$

The damping derivative is given by,

$$
-C_{m_{q}}=\frac{1}{\frac{1}{2} \rho_{\infty} U_{\infty} L^{3}}\left(-\frac{\partial m}{\partial q}\right)
$$

The damping derivatives are evaluated at $\alpha=\alpha_{0}$ and $\mathrm{q}=0$, and the Piston Mach number is given by

$$
M_{p}=\frac{1}{a_{\infty}}\left[U_{\infty} \operatorname{Sin}^{2} \alpha+\left(x-x_{o}\right) \mathrm{q}\right]
$$


By combining Eq. (2 and 3)differentiation within the integral sign and integration are performed. Defining $h=\frac{x_{0}}{c}, \mathrm{x}_{0}=\mathrm{hL} \cos ^{2} \alpha_{0}, S_{1}=\frac{M_{\infty} \sin \alpha_{O}}{\cos \phi}$ Multiplying by 2 for effects of two sides and replacing L by C in non-dimensionalizing, the derivatives of a plane wedge are

$C_{m_{q}}=\frac{(\gamma+1)}{M_{\infty}}\left\{\frac{F\left(S_{1}\right)}{\cos \emptyset \cos ^{3} \alpha \circ}\right\}\left\{\frac{1}{3}-h \cos ^{2} \alpha_{\circ}+h^{2} \cos ^{4} \alpha_{\circ}\right\}$

Where,

$$
F\left(S_{1}\right)=2 S_{1}+\frac{B+2 S_{1}^{2}}{\sqrt{B+S_{1}^{2}}}
$$

Results of damping derivatives for various Mach numbers in the range $M=2$ to 4 and angle of incidences from 5 to 25 degrees have been studied.

\section{Results And Discussions}

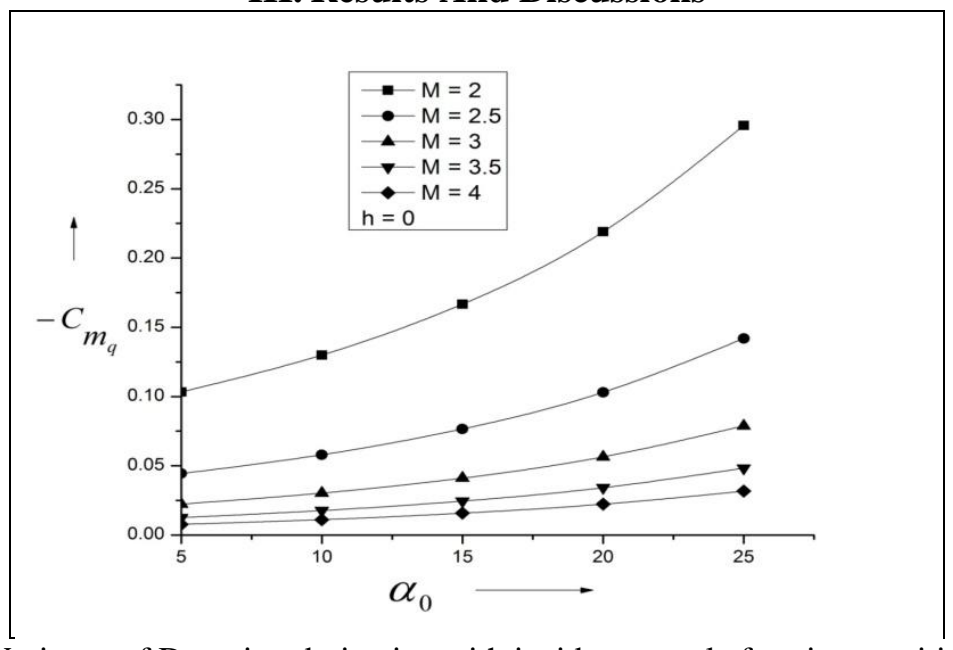

Fig.1: Variance of Damping derivative with incidence angle for pivot position $\mathrm{h}=0$

Fig. 1 demonstrates the changes in Damping derivative with incidence angle for pivot position at $\mathrm{h}=0$, i.e. at the nose of the wedge. Damping derivative has a linear increment up to 15 degrees with respect to incidence angle then non-linearity creeps in. The magnitude of the damping derivatives is varying from 0.105 to 0.01 for the inertia level of $\mathrm{M}=2$ to 4 . Here the damping derivatives are evaluated with the pitch rate coupled with the angle of attack. The non-linear behavior may be due to the combined effect of rate of pitch, angle of attack, strength of the shock wave and the pressure distribution.

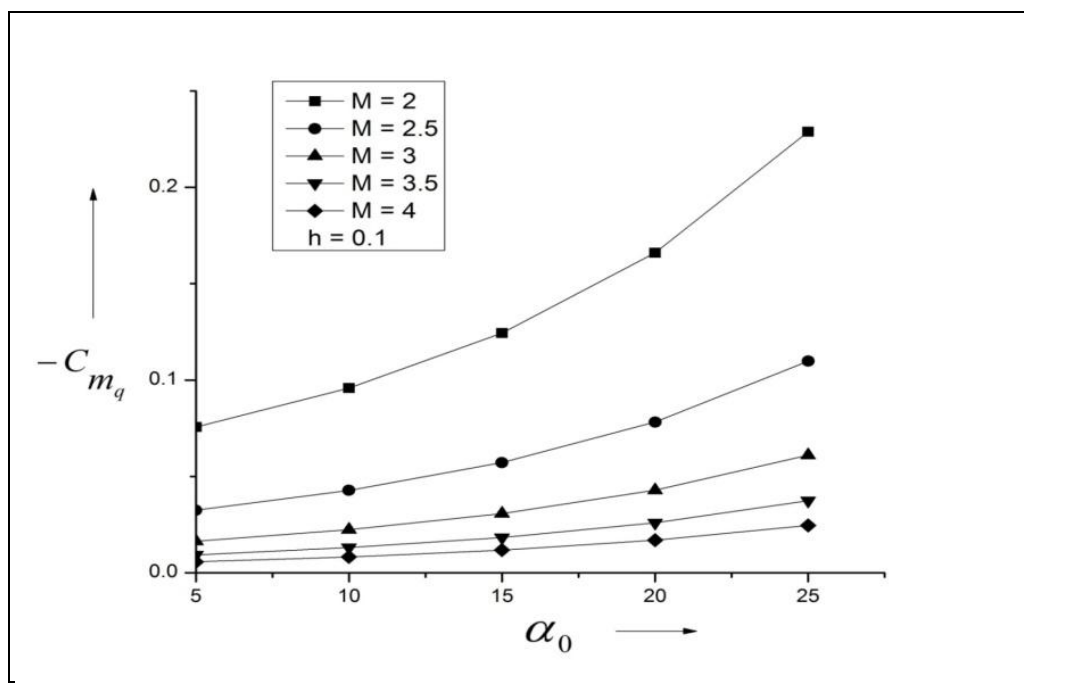

Fig. 2: Variance of Damping derivative with incidence angle for pivot position $\mathrm{h}=0.1$ 
Fig. 2 gives the damping derivative with incidence angle where in position of pivot is shifted $10 \%$ away from the nose of the wedge towards the trailing edge. There is a reduction in the value of damping derivative with incidence angle when pivot shifts from 0 to 0.1 and the values are in the range from 0.08 to 0.005 , however, the trend is the same as that of for $\mathrm{h}=0$. This reduction in the magnitude could be attributed to the shift in the pivot position, shift in the plan form area, when combined with the rate of pitch and angle of attack.

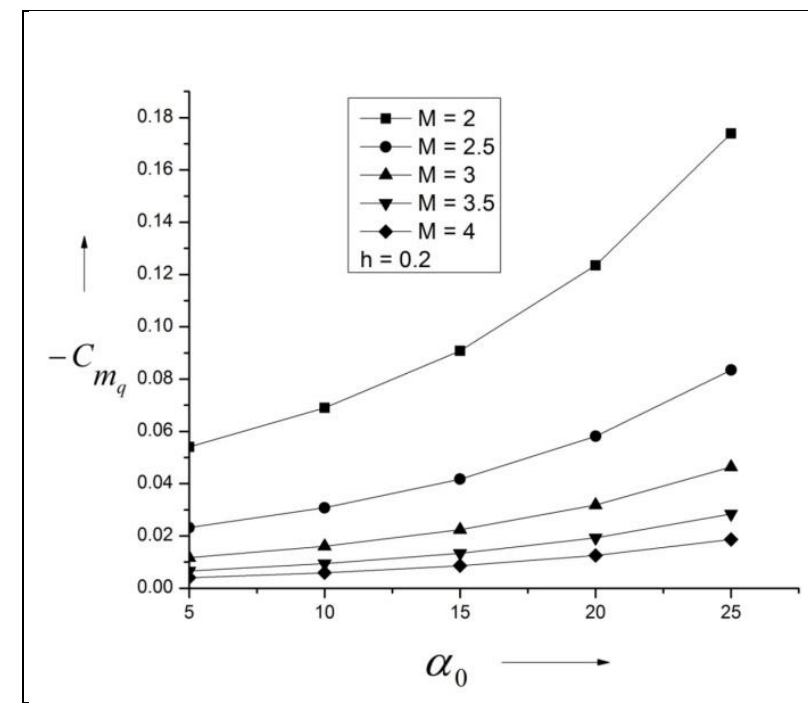

Fig. 3: Variance of Damping derivative with incidence angle for pivot position $h=0.2$

Fig. 3 gives the variation in the damping derivative with incidence angle where in pivot position is at $20 \%$ from the nose. There is a further reduction in the value of Damping derivative with incidence angle when pivot shifts from 0 to 0.2 when these values are compared with those for $\mathrm{h}=1$. These values are ranging from 0.055 to 0.005 , it is seen that the values at angle of attack 5 degrees and Mach number $\mathrm{M}=4$ are unchanged however, the values for Mach number $\mathrm{M}=2$ for the angle of attack of degrees has further decreased. Once again it reiterates that due to the further shift in the pivot position and hence the plan form area has caused reduction in the values.

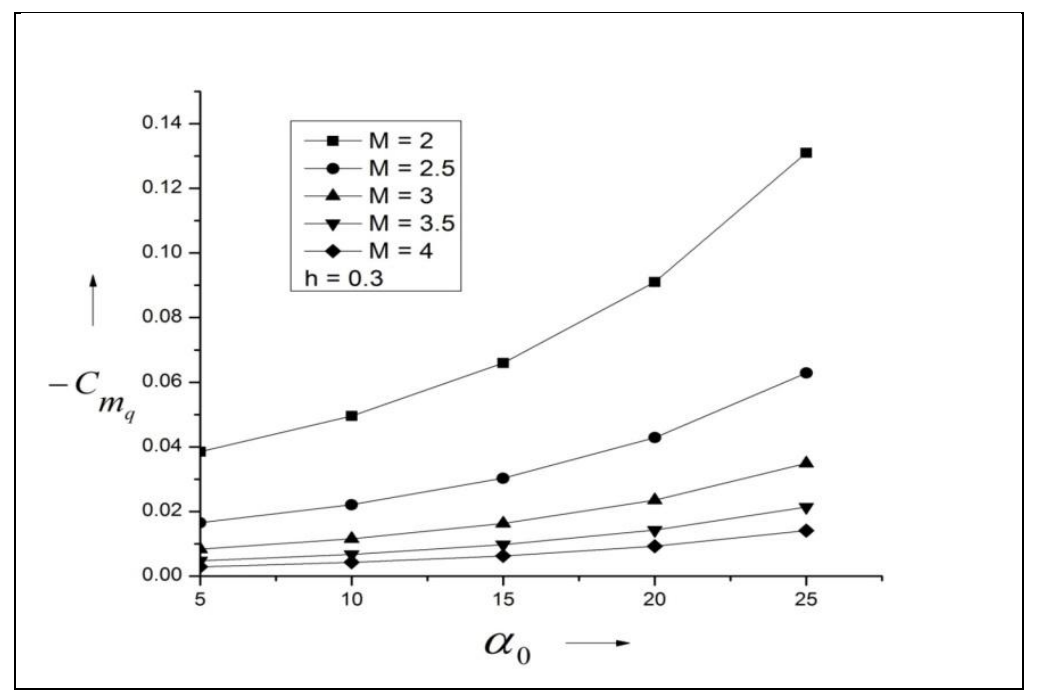

Fig. 4: Variance of Damping derivative with incidence angle for pivot position $h=0.3$

Fig. 4 shows the change in damping derivative with incidence angle, where in the position of pivot is shifted $30 \%$ away from the nose. There is further reduction in the value of damping derivative with incidence angle when pivot shifts from 0.2 to 0.3 , and the values have come down in the range from 0.04 to 0.005 , otherwise the trend remains the same as discussed earlier. 


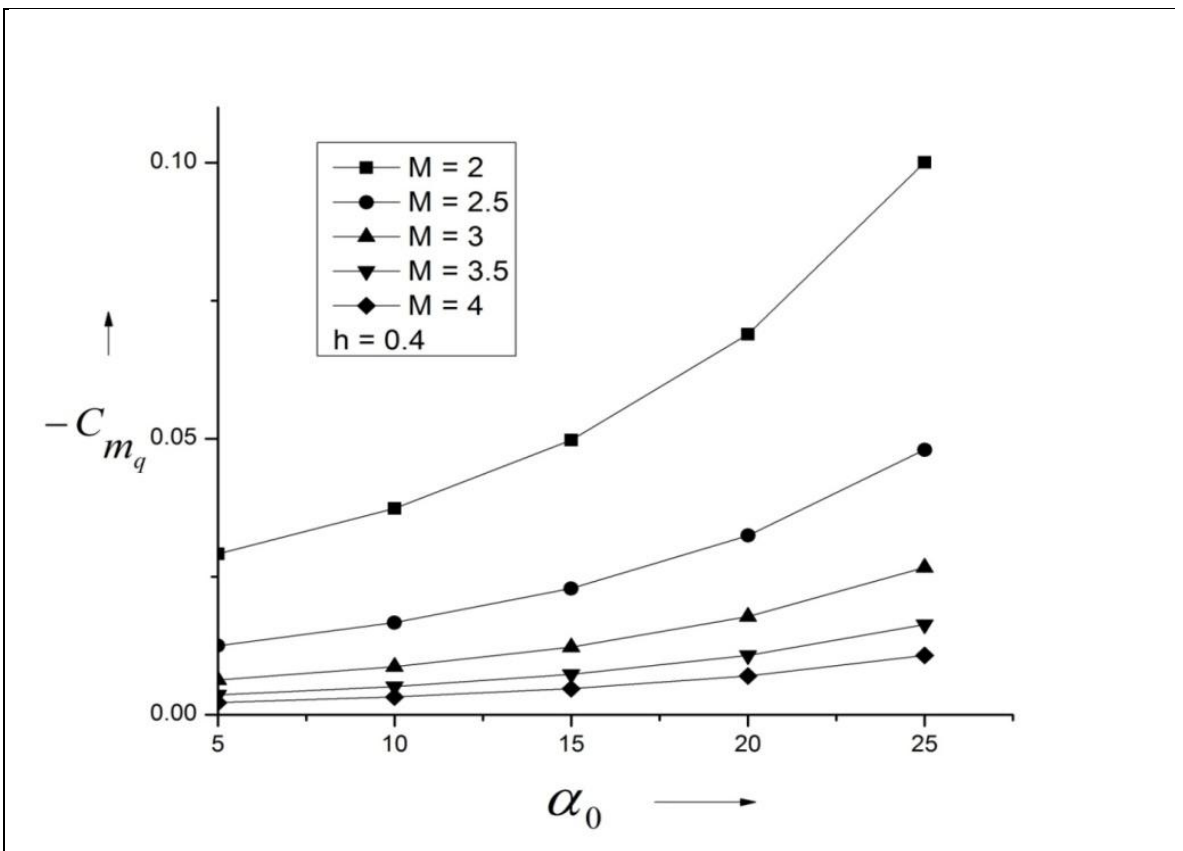

Fig. 5: Variance of Damping derivative with incidence angle for pivot position $h=0.4$

Fig. 5 gives the change in damping derivative with incidence angle for pivot at $\mathrm{h}=0.4$. There is a further reduction in the value of damping derivative with incidence angle when pivot shifts from 0 to 0.4 and their values are in the range from 0.03 to 0.002 , otherwise the same trend is seen as discussed earlier.

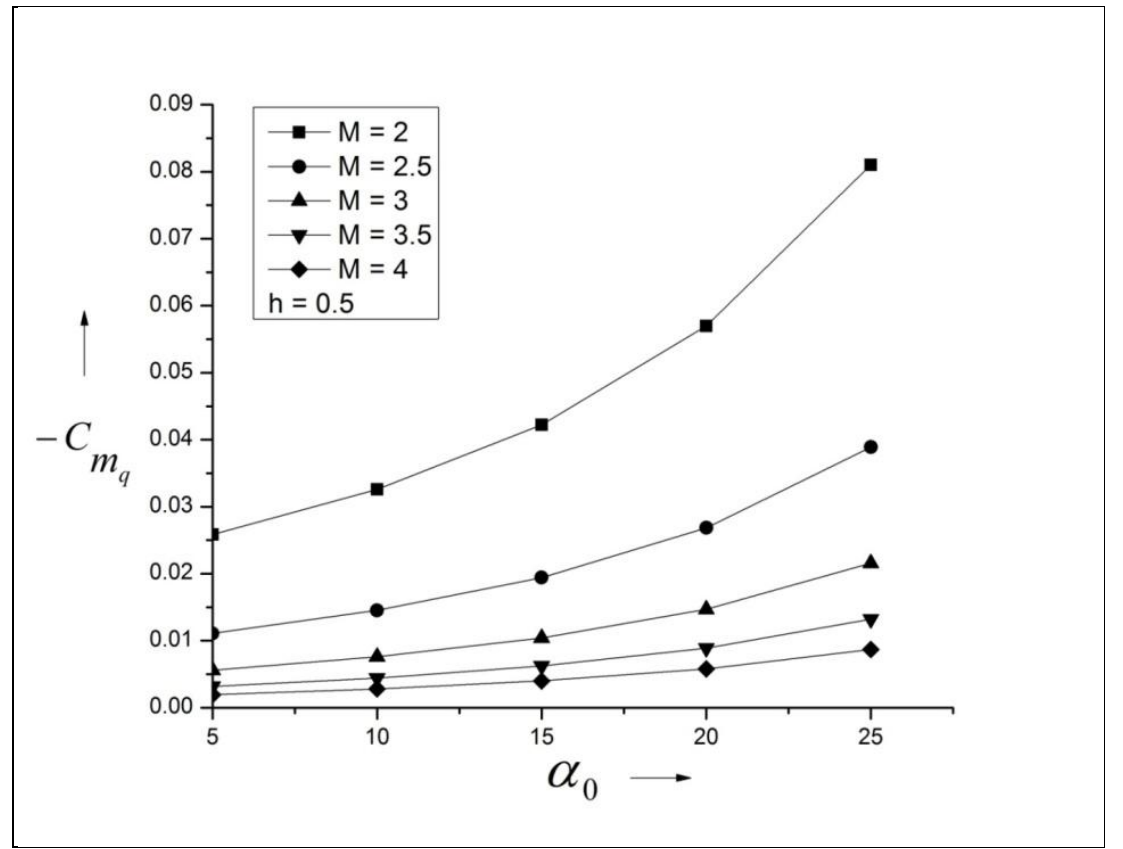

Fig. 6: Variance of Damping derivative with incidence angle for pivot position $h=0.5$

Fig. 6 gives the results for change in the damping derivative with incidence angle where in pivot position is $h=0.5$. There is a further reduction in the value of Damping derivative with incidence angle when pivot position has been shifted to $h=0.5$ and it is clearly visible it is actually attaining a minima at $h=0.5$. The attainment of minima is due to the pivot position being much closed to the center of pressure. 


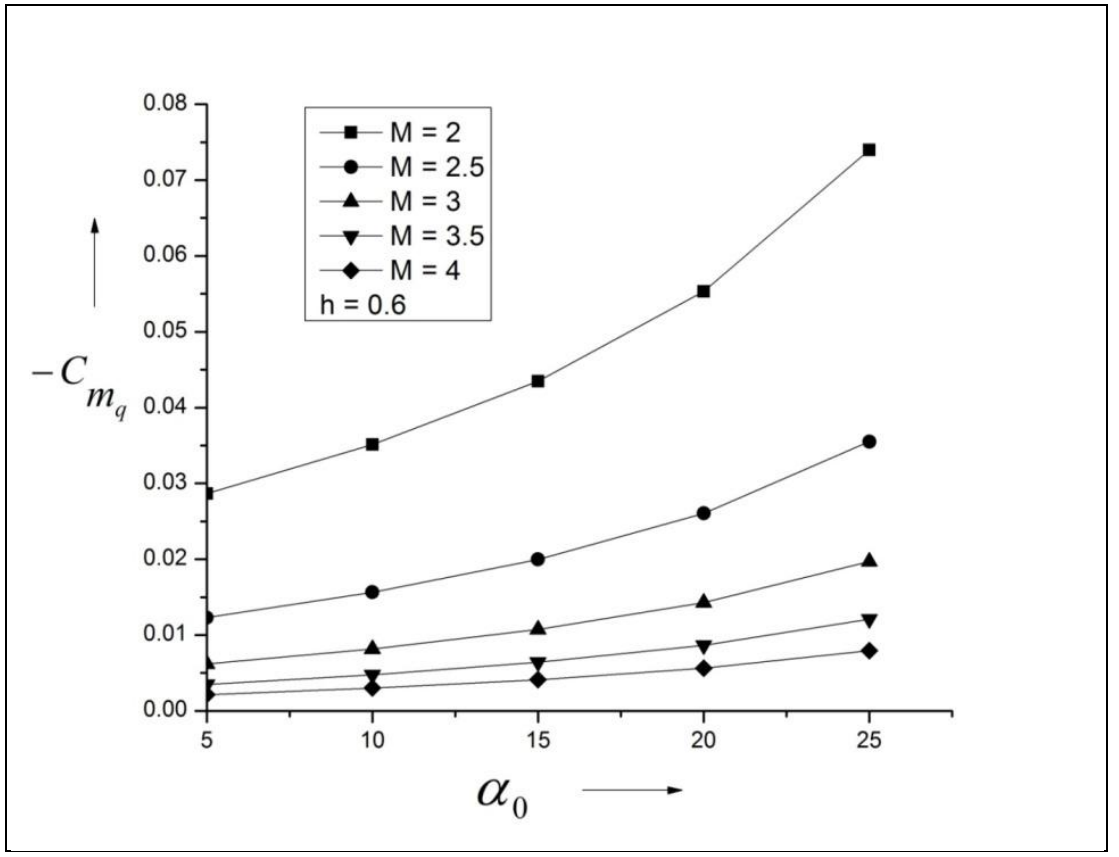

Fig.7: Variance of Damping derivative with incidence angle for pivot position $h=0.6$

Fig.7 presents the damping derivative with incidence angle where in position of pivot is shifted $60 \%$ away from the nose of the wedge. Here it is seen that after attaining a minima again there will be increase in the value of damping derivative and they are in the range from 0.028 to 0.002 , also it is seen that at Mach number $\mathrm{M}$ $=4$ it remained steady for the last three pivot positions namely $\mathrm{h}=0.4$ to 0.6 , this may due to the distribution of the plan form area, location of pivot position and the pressure distribution.

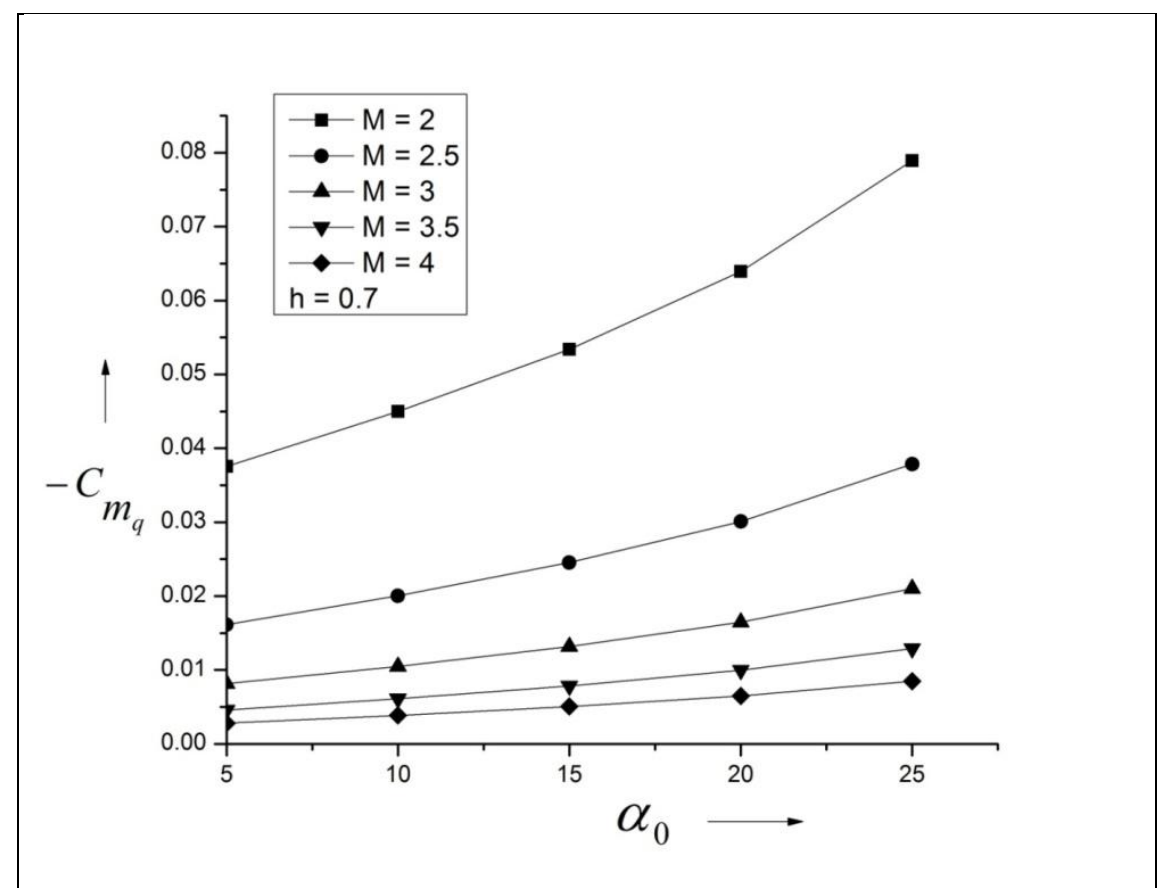

Fig. 8: Variance of Damping derivative with incidence angle for pivot position $h=0.7$

Fig. 8 gives the change in damping derivative with incidence angle for pivot position $\mathrm{h}=0.7$ from the nose of the wedge. There is a increase in the value of Damping derivative with incidence angle when pivot shifts from 0.6 to 0.7 , and values are in the range from 0.038 to 0.004 it seen that there is progressive increase in the stability derivative in pitch for all the Mach numbers as compared to the previous value and trend remains the same. 


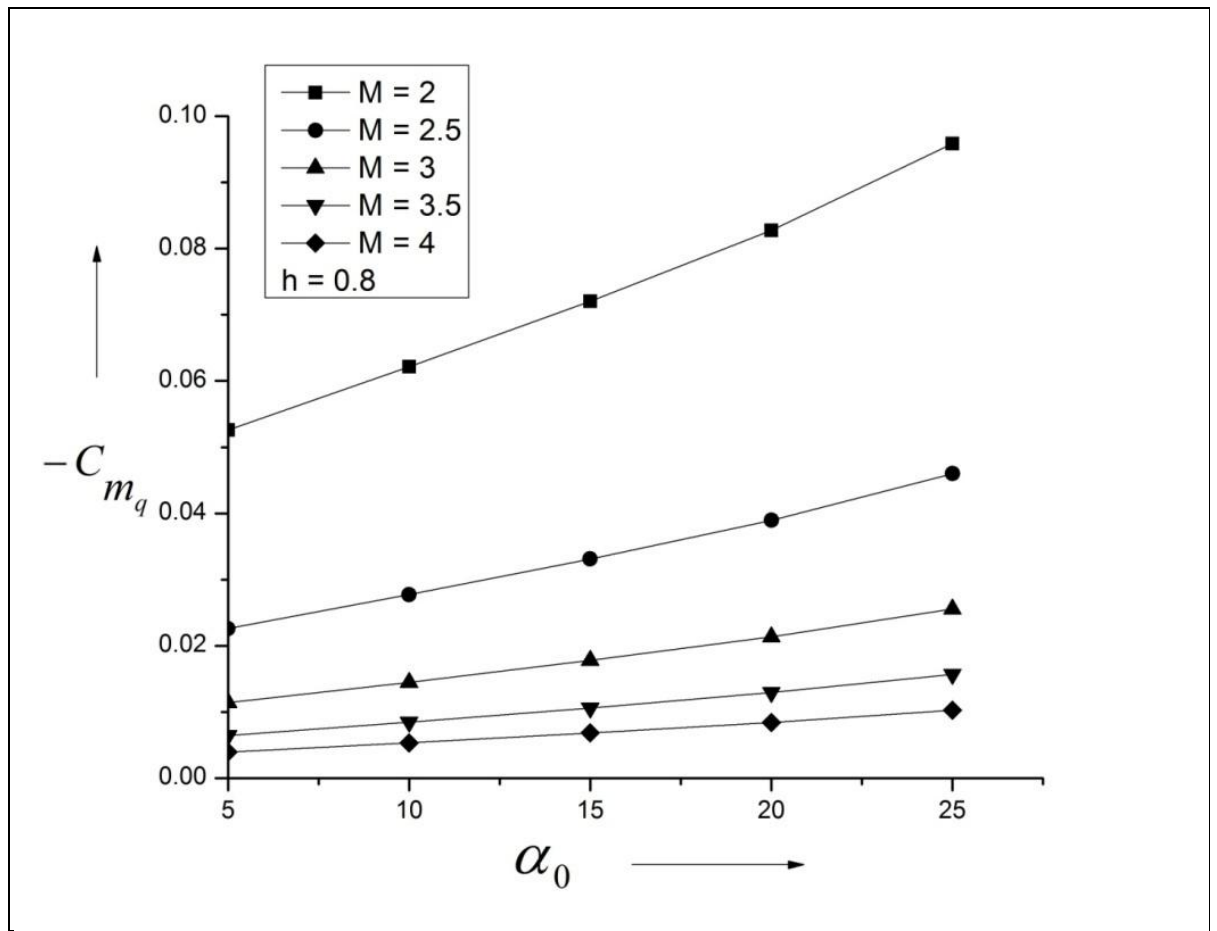

Fig. 9: Variance of Damping derivative with incidence angle for pivot position $h=0.8$

Fig. 9 gives the distribution of the damping derivative in pitch with incidence angle where in position of pivot is $80 \%$ away from the nose of the wedge. There is further increase in the value of the damping derivative with incidence angle when pivot shifts from 0.7 to 0.8 and this value lies between 0.054 to 0.004 , there is over all enhancement the stability derivative else trend remains the same.

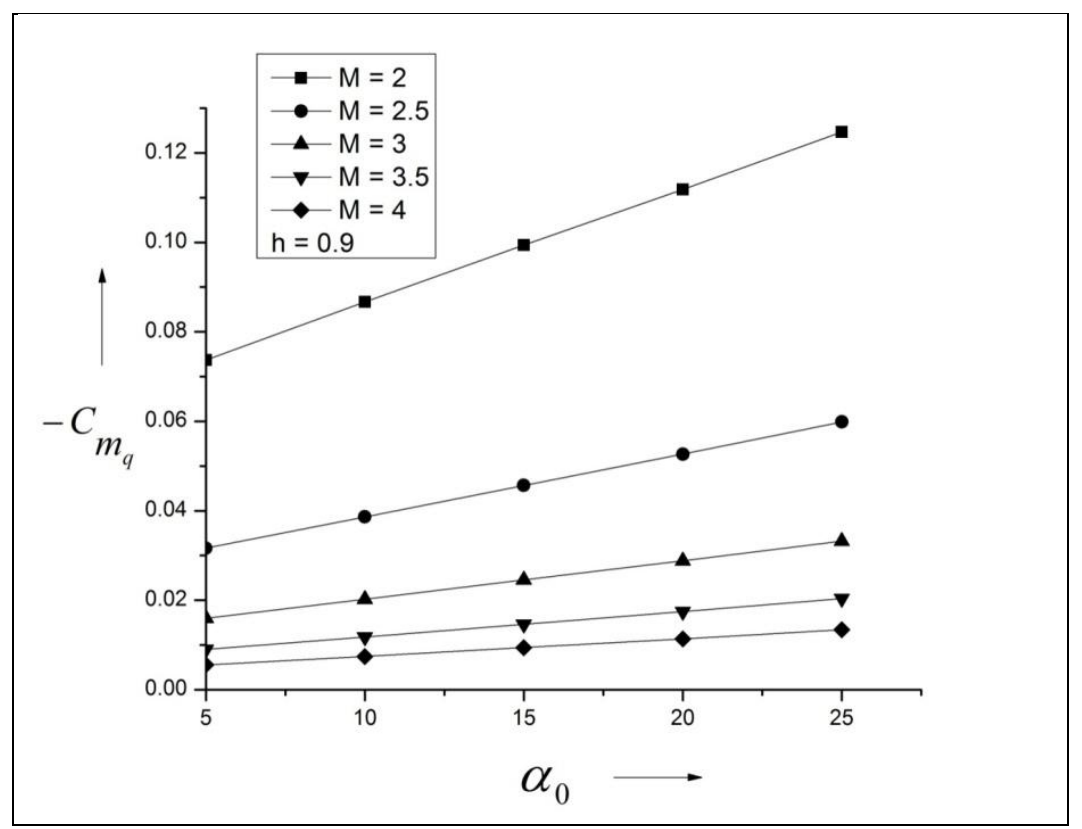

Fig. 10: Variance of Damping derivative with incidence angle for pivot position $h=0.9$

Fig. 10 gives the variation of damping derivative with incidence angle where in position of pivot is at $10 \%$ from the trailing edge of the wedge. There is further increase in the value of damping derivative with incidence angle when pivot shifts from 0.8 to 0.9 and these are in the range from 0.075 to 0.006 showing similar trend as discussed earlier. 


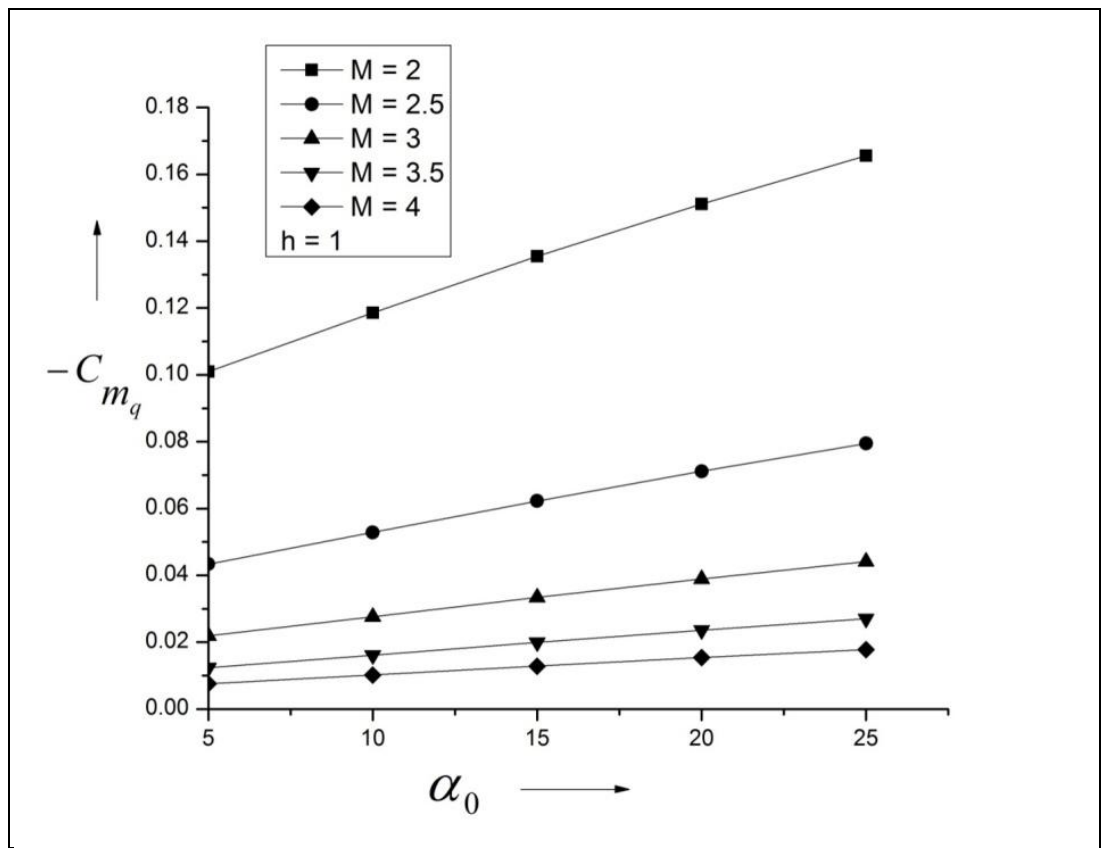

Fig.11: Variance of Damping derivative with incidence angle for pivot position $h=1$

Fig.11 gives the variation in the stability derivative in pitch with incidence angle where in position of pivot is $\mathrm{h}=1$, which is the trailing edge of the wedge, it is interesting to note that the magnitude of the damping derivative at $h=0$ and $h=1.0$ are identical and they lie in the range from 0.105 to 0.008 . There trend with the increase in the angle of incidence remains the same.

\section{Conclusion}

Based on the above discussion the following conclusion can be drawn:

- The Damping derivative decreases with Mach number and increases with the incidence angle.

- It is also seen that for a given Mach number the damping derivatives are decreasing and reaches a minimum value and then again increases and attains the same value which was at $h=0$, for Mach number $M=2$, however, the magnitude of damping derivative remains smaller as compared to the value at $h=0$ for Mach number due to the different pressure distribution, rate of pitch, shift in the center of pressure.

- It is also seen that for pivot position $h=0$ to $h=1.0$ and at $h=0.5$ it attains a minima and then again it increases for $\mathrm{h}=0.6$ to $\mathrm{h}=1$.

- The damping derivative decreases with Mach number for the varying pivot position, whereas, it continue to increase with the angle of attack.

- The results are valid as long as the shock waves are attached, and we are considering the weak solution when the oblique shock wave is formed at the nose of the wedge.

\section{References}

[1]. Ghosh, K. (1977), "A New Similitude for Aerofoils in Hypersonic Flow", Proceedings of the $6^{\text {th }}$ Canadian Congress of Applied Mechanics, Vancouver, Canada, May 29-June 3, pp. 685-686.

[2]. Ghosh K., and Mistry B.K. (1980), "Large incidence Hypersonic Similitude and Oscillating Non-planar Wedges", AIAA Journal, Vol.18, Number 8, Aug. pp. 1004-1006.

[3]. Ghosh, K. (1984), "Hypersonic Large Deflection Similitude for Quasi wedges and Quasi-cones", Aeronautical Journal, March, pp. 70-76.

[4]. Asha Crasta and S. A. Khan, "High Incidence Supersonic similitude for Planar wedge",International Journal of Engineering research and Applications, Vol.2, Issue 5, September-October 2012, pp. 468-471.

[5]. Asha Crasta and S. A. Khan, "Estimation of Stability derivatives of an Oscillating Hypersonic delta wings with curved leading edges",IJMET, Vol.3, Issue 3, December 2012, pp. 483-492.

[6]. Asha Crasta, M. A. Baig, S. A. Khan, 2012, 'Estimation of Stability derivatives of a Delta wing in Hypersonic flow', International Journal of Emerging trends in Engineering and Developments, Vol. 6, Issue2, Sep., pp. 505-516.

[7]. Asha Crasta and Khan S. A, 2012, 'Oscillating Supersonic delta wing with Straight Leading Edges', International Journal of Computational Engineering Research, Vol. 2, Issue 5, September, pp. 1226-1233.

[8]. Asha Crasta and S. A. Khan , "Determination of Surface Pressure of an axisymmetric ogive in Hypersonic Flow" in Mathematical sciences International Research Journal, Vol. 2, Issue2,August 2013,pp.333-335,ISSN:2278-8697. 
[9]. Asha Crasta and S. A. Khan, 2013, 'Stability Derivatives in the Newtonian Limit', International Journal of Advanced Research in Engineering and Technology, Volume 4, Issue 7, Nov-Dec., pp. 276-289.

[10]. Asha Crasta and S.A. Khan, 2014, 'Estimation of Stability Derivatives for a Planar Wedge in the Newtonian Limit', IOSR Journal of Mathematics, Volume10, Issue 2 Version I, March-April, pp. 01-06.

[11]. Asha Crasta and S. A. Khan, 2014, 'Effect of Mach number on Stiffness and Damping Derivatives for Oscillating Hypersonic Non-Planar Wedge', IOSR Journal of Mechanical and Civil Engineering, Volume 11, Issue 2 Ver. VIII (Mar- Apr.), pp. 04-11.

[12]. Asha Crasta and S.A. Khan, 2014, 'Effect of Angle of Incidence on Stiffness and Damping derivatives for Oscillating Hypersonic Non-planar Wedge', International Journal for Research in Applied Science and Engineering Technology, Vol. 2, Issue IV, April 2014, pp. 229-242.

[13]. Asha Crasta and S.A. Khan, 2014, 'Supersonic Similitude for Oscillating Non-Planar wedge',IOSR Journal of Mathematics,Volume10, Issue 2 Ver.VI ,Mar-Apr 2014,pp.15-24.

[14]. Asha Crasta and Khan S. A., 2014, 'Stability derivatives of a Delta Wing with Straight leading edge in the Newtonian Limit', International Journal of Engineering research and Applications, Vol. 4, Issue 3, Version 2, March, pp. 32-38.

[15]. Asha Crasta, S. A. Khan , 2014, 'Effect of angle of incidence on Roll damping derivative of a delta Wing', International Journal of Emerging trends in Engineering and Developments Vol. 2, Issue4, March 2014, pp. 343-356.

[16]. Asha Crasta and S.A. Khan, 2014, 'Effect of Angle of Incidence on Stability derivatives of a wing', International Journal for Research in Applied Science and Engineering Technology, Vol. 2, Issue V, May, pp. 411-422.

[17]. Asha Crasta and S. A. Khan, 2014 ,'Effect of Angle of attack on Stability derivatives of a Delta wing with Straight leading edge in Supersonic Flow',International Journal of Mathematics,Vol.10,issue5,Sep-oct 2014. Pp. 01-08.

[18]. Asha Crasta and S. A. Khan, 2014, 'Hypersonic similitude for planar wedges', International Journal of Advanced Research in Engineering and Technology, Volume 5, Issue 2, Feb., pp. 16-31.

[19]. Asha Crasta, S. A. Khan , 2014, 'Effect of sweep angle on Roll damping derivative of a delta Wing', International Journal of Emerging trends in Engineering and Developments Vol15, Issue4, Aug-Sep, pp. 45-55.

[20]. Asha Crasta and S. A. Khan, 2014,'Effect of Angle of attack on Stability derivatives of a Delta wing in Hypersonic flow with Straight leading edge',International Journal of Mechanical and civil engineering,Vol.11,issue5,Sep-oct (ver.2). Pp. 21-29.

[21]. Asha Crasta and S.A.Khan 2014," Effect of sweep angle on rolling moment derivative of an oscillating supersonic/hypersonic delta wing", International journal of modern Engg. Research, Vol.4, issue 10,ver3, pp.15-22.

[22]. Asha Crasta and S. A. Khan 2015, "Effect of Angle of attack on Stiffness derivative of an oscillating supersonic delta wing with curved leading edges" IOSR-JMCE issue1, Volume12, December,pp12-25.

[23]. Asha Crasta and S. A. Khan, "Effect of Angle of attack on Damping derivative of a delta wing with full sine curved leading edges" IJETED Journal issue5, Volume1, December- January 2015.

[24]. Asha Crasta and S. A. Khan,2015 "Estimation of Damping derivative of a delta wing with half sine curved leading edges" IOSR Journal of Mechanical and civil engineering, Vol.12, issue1,February ,pp40-44.

[25]. Asha Crasta and S. A. Khan 2015, "Estimation of Damping derivative in pitch of a Supersonic delta wing with curved leading edges" IOSR Journal of Journal of Mathematics , Vol. 11,issue 1, Jan-feb ,pp.07-15.

[26]. Asha Crasta and S.A.Khan 2015,'Effect of Aspect ratio with angle of attack of an oscillating Hypersonic delta wing with Straight Leading edges", Mathematical Sciences International research Journal",volume 4,issue2, pp.28-33., ISSN2278-8697.

[27]. Asha Crasta and S.A. Khan,2016,"Effect of Aspect ratio with roll moment derivative of a delta wing in supersonic flow", International Journal of Advances in Engineering Research, (IJAER) 2016, Vol. No. 12, Issue No. I, July,pp.10-15, e-ISSN: 2231-5152, p-ISSN: 2454-1796.

[28]. Khan S. A. and Asha Crasta, "Oscillating Supersonic delta wings with curved leading edges",Advanced Studies in Contemporary mathematics, Vol. 20 (2010), No.3, pp. 359-372. 